\title{
Physicochemical Evaluation of Diploknema butyracea Seed Extract and Formulation of Ketoconazole Ointment by Using the Fat as a Base
}

\author{
Jitendra Pandey $\mathbb{D}^{D}$, Bimal Khanal, Jhabilal Bhandari, Rishav Bashyal, Asmita Pandey, \\ Asgar Ali Mikrani, Pramod Aryal $\mathbb{D}$, and Ravin Bhandari $\mathbb{D}$
}

Department of Pharmacy, Crimson College of Technology, Affiliated to Pokhara University, Devinagar-11, Butwal 32900, Nepal

Correspondence should be addressed to Jitendra Pandey; jitupandey01301@gmail.com and Ravin Bhandari; ravinbhandari2000@ gmail.com

Received 31 December 2020; Revised 28 September 2021; Accepted 29 October 2021; Published 16 November 2021

Academic Editor: Tatsadjieu Ngouné Léopold

Copyright (c) 2021 Jitendra Pandey et al. This is an open access article distributed under the Creative Commons Attribution License, which permits unrestricted use, distribution, and reproduction in any medium, provided the original work is properly cited.

\begin{abstract}
The fat obtained from the ripened seeds of Diploknema butyracea is widely used as a vegetable oil in rural areas of Nepal. This study was aimed for the physicochemical evaluation (acid value, iodine value, saponification value, peroxide value, ester value, $\mathrm{pH}$, and liquefaction point) of the Diploknema butyracea seed extract (chyuri fat) and the formulation of $2 \% \mathrm{w} / \mathrm{w}$ ketoconazole ointment by using it as a base. All the physicochemical parameters were determined quantitatively by using the method of Indian Pharmacopoeia (IP), volume-I. By fusion method, 3 different formulations F-A, F-B, and F-C were prepared, in which different proportions of chyuri fat, polyethylene glycol 6000 (PEG 600), Tween 80, and propylene glycol were used as an ointment base. Various quality parameters such as spreadability, extrudability, viscosity, smoothness, $\mathrm{pH}$, average fill weight, assay, content uniformity, accelerated stability, and drug release profiles were determined. HPLC was used for the determination of ketoconazole content in the ointment formulations. Physicochemical evaluation of the chyuri fat ensured its suitability for industrial purpose. The active ingredient release profile of formulations F-A (87.71\%), F-B (88.89\%), and F-C $(91.09 \%)$ after 5 hours were within acceptable range along with other parameters. Assay of the formulations F-A, F-B, and F-C were reported to be 103.01, 107.9, and $102.45 \%$, respectively. Overall, evaluation of the formulation F-A, prepared by using chyrui fat only, gave satisfactory results and most of the parameters were statistically similar $(p>0.05)$ to the F-B and F-C formulated by incorporating a certain proportion of synthetic base. Thus it can be concluded that chyuri fat can be the best alternative to replace the expensive synthetic base.
\end{abstract}

\section{Introduction}

Diploknema butyracea Roxb (family: Sapotaceae) is a medium-sized deciduous tree having a height of about $20 \mathrm{~m}$ $[1,2]$. The plant is native to the Himalayan region, widely distributed to Nepal, India, and Bhutan up to an altitude of $300-1500 \mathrm{~m}$. It is popular with the name "Chyuri" in Nepal, "Indian-butter nut" in English, and "Chiura" or "Phulwara" in India $[1,3]$. Diverse parts of this plant have been used by ethnic groups of Nepal and India mainly for food and medicinal purpose [4]. Juice is prepared from the stem bark to treat digestive complications, helminthiasis, asthma, ulcers, leprosy, and rheumatoid arthritis [5]. Corolla is expressed to get the sweet juice that is eaten fresh or boiled to obtain syrup [6]. The most applicable part of the plant is the edible seed. Chyuri seed contains about 55\% fat (chyuri butter), which is used as vegetable oil as well as massage oil for rheumatism, headache, acne, and boils [7]. The chyuri fat is a very useful natural emollient for cracked feet and hands in the winter season [5, 7]. Similarly, chyuri fat has been utilized as butter for oil lamps, hair oil, and raw material for toilet soap. Moreover, many commercial organizations have done experiments to prepare many commercial products such as chyuri syrup, chyuri squash, chyuri jam, and chyuri cream [8]. 
Nowadays, interest in the study of plant-derived fat and oils is increasing tremendously to utilize them as a vehicle for diverse pharmaceutical topical preparations $[5,9]$. Delivery of the drug through the topical route has long been proved to be a promising approach due to the large surface area of the skin, ease of access, wide exposure to the circulatory and lymphatic system, and confined nature of the treatment [9]. Among different topical preparations, ointments are semisolid homogenous formulations prepared for external application to the skin or mucous membranes. Ointments are commonly used as emollients or to administer the active drugs on the skin for preventive, therapeutic, or protective purposes and where occlusion of the certain body part is required. Various antifungal drugs are available commercially in the form of different topical formulations such as ointment, cream, and powder [10].

Ketoconazole is one of the potent broad-spectrum antifungal drugs which belong to the synthetic imidazole group. It is lipophilic in nature and practically insoluble in water $[11,12]$. It is characterized as biopharmaceutical classification system (BCS) class IIb drug [13]. The drug has a significant therapeutic effect against systemic and superficial mycosis along with Candida, Malassezia, and dermatophyte $[10,14]$. It inhibits the synthesis of fungal ergosterol, a key constituent of the fungal cell membrane, resulting in cell death. Besides, it also interferes with the biosynthesis of fungal phospholipids, triglycerides, and oxidative enzymes, increasing the cellular concentration of the toxic hydrogen peroxide. For the treatment of Candida albicans infection, it prevents the formation of invasive mycelia from the blastopores [15].

Despite the increasing demand of topical drug delivery system (ointment, cream, gel, etc.), still many problems exist, such as chemical instability of the base, necessity of many excipients to ensure the stability, high cost for the production of synthetic base, and hypersensitivity reaction of the base to the skin. This dire condition has compelled us to explore the more successful natural source. Chyuri fat has a long history of economical and ethnomedicinal importance to different ethnic groups in Nepal and it has been used as one of the chief components in many commercial preparations by cosmetic, pharmaceutical, and soap industries [8]. Hence, this study aimed to evaluate the physicochemical parameters and formulate $2 \% \mathrm{w} / \mathrm{w}$ ketoconazole ointment by using chyuri fat as an ointment base along with analysis of the ointment quality and stability.

\section{Materials and Methods}

2.1. Chemicals. Ketoconazole powder $(99.18 \%$ pure with $0.11 \%$ loss on drying) was obtained as a gift from the Biogain Remedies, Pvt., Ltd., Rupandehi, Nepal. We also used tetrabutylammonium sulphate (SD Fine-Chem Limited, Mumbai), iodine trichloride and sodium thiosulphate (Fischer Scientific Pvt., Ltd., India), cellophane membrane (Yiwu Eco-Tondo Artware Co., Ltd., China), potassium iodide and potassium bromate (Merck Limited, India), Tween 80, propylene glycol, polyethylene glycol 600 (PEG 6000), and iodine and mercuric iodide (Qualigens Fine chemicals, India).
2.2. Plant Collection. Healthy and mature fruits of the Diploknema butyracea were collected from Tansen, Palpa district, Nepal (1350 $\mathrm{m}$ above from the sea level), in July 2019. Identification and authentication of the plant were done with the help of an investigation officer (Ms. Pratikshya Chalise) of National Herbarium and Plant Laboratories, Godawari, Lalitpur, Nepal (ref. no. 075/076363). The voucher specimen was properly labeled and preserved in the Pharmacognosy Laboratory, Department of Pharmacy, Crimson College of Technology (specimen number: CCT/ $\mathrm{HRB} / 2019-212)$.

\subsection{Extraction of D. butyracea Seeds. Fruits of D. butyracea} were first separated into peel and pulp. Seeds were taken out from the pulp manually. All the seeds were peeled manually (Figure 1) and were outspread over the clean filter paper, kept in the well-ventilated laboratory room $25^{\circ} \mathrm{C}$ for 2 weeks. Filter papers were changed every day to protect from the possible fungal contamination. After the complete drying, seeds were ground to powder of size as small as possible with the help of a grinding machine. The sticky coarse fine powder mass was then extracted by using a cold triple maceration method in which $200 \mathrm{~g}$ of dried powder was immersed with $1000 \mathrm{~mL}$ hexane in the conical flasks with frequent shaking for 1 day. The menstruum was strained; the marcs were pressed and then subjected to filtration. The process was continued for 3 times and all the filtrate was collected together. The filtrate was dried by using a rotary vacuum evaporator at $40^{\circ} \mathrm{C}$ to obtain thick, viscous fat (Figure 2) which was again dried by using a vacuum desiccator. Finally, the dried extract was preserved at $4^{\circ} \mathrm{C}$ until use.

2.4. Physicochemical Evaluation of the Chyuri Fat. Physicochemical analysis was carried out by adopting the methods described in the Indian Pharmacopoeia (IP) 2018 [16].

2.4.1. Acid Value. About $10 \mathrm{~g}$ of the sample was weighed in the round bottom flask and dissolved in $50 \mathrm{~mL}$ of the previously neutralized mixture of the $95 \%$ ethanol and ether $(1: 1 \mathrm{v} / \mathrm{v})$. After that, a reflux condenser was connected and warmed slowly with frequent shaking to dissolve the sample. Then, the sample solution was titrated with standardized $0.1 \mathrm{M}$ potassium hydroxide and endpoint was detected. Phenolphthalein solution was used as an indicator. Finally, acid value was calculated from the following equation:

$$
\text { acid value }=\frac{5.61 n}{w}
$$

where $n$ is the volume of $0.1 \mathrm{M}$ potassium hydroxide consumed $(\mathrm{mL})$ and $w$ is the weight of the sample $(\mathrm{g})$.

2.4.2. Iodine Value. Iodine value was determined by using the Hanus method. At first, $290.4 \mathrm{~g}$ of the sample was placed in a $300 \mathrm{~mL}$ of dry iodine flask and dissolved in $15 \mathrm{~mL}$ of chloroform. Then, $25 \mathrm{~mL}$ of iodine monobromide solution 


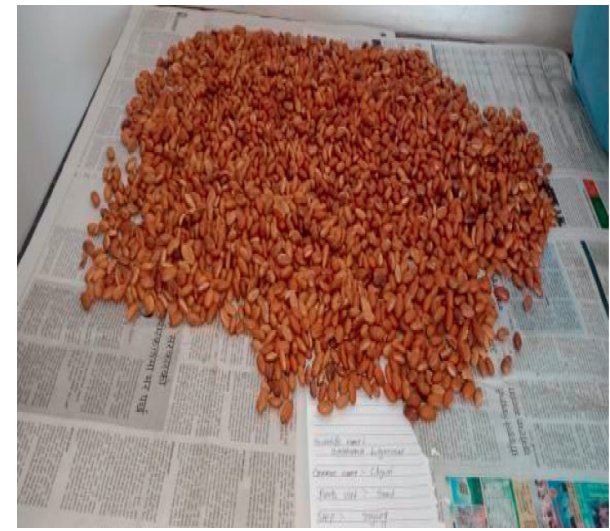

FIgURE 1: Seeds of D. butyracea.

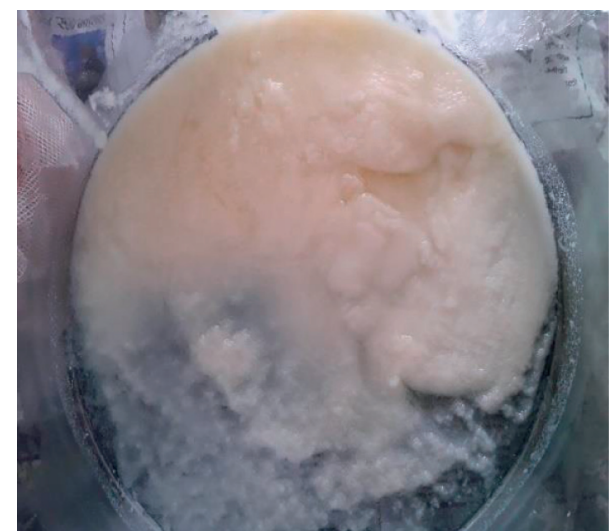

Figure 2: D. butyracea dried hexanolic extract (chyuri fat).

was added slowly from the burette. The sample was kept in a dark place for 30 minutes with frequent shaking. After that, $10 \mathrm{~mL}$ of $30 \% \mathrm{w} / \mathrm{v}$ of potassium iodide solution and $100 \mathrm{~mL}$ of water was added followed by titration with standardized $0.1 \mathrm{M}$ sodium thiosulphate using starch solution as an indicator during the end of the titration. The volume of $0.1 \mathrm{M}$ thiosulphate $(\mathrm{mL})$ consumed was noted as (a). The same operation was repeated without using sample, and volume consumed $(\mathrm{mL})$ was noted as (b). The iodine value was calculated by using the following equation:

$$
\text { iodine value }=\frac{1.269(b-a)}{290.4} .
$$

2.4.3. Saponification Value. About $2 \mathrm{~g}$ of the sample was kept into a $250 \mathrm{~mL}$ round bottom flask and fitted with a reflux condenser. After that, $25 \mathrm{~mL}$ of the ethanolic $0.5 \mathrm{M}$ potassium hydroxide and pumice powder was poured and boiled over a water bath for $30 \mathrm{~min}$. The sample was allowed to cool for a few minutes. Finally, the sample solution was titrated against $0.5 \mathrm{M}$ hydrochloric acid $(\mathrm{HCl})$ using phenolphthalein as an indicator. Blank titration was also performed without adding sample. The saponification value was calculated from the following equation:

$$
\text { saponification value }=\frac{28.5(b-a)}{w},
$$

where $w$ is the weight of the sample in $g$ and $b$ and $a$ are the volume of the $\mathrm{HCl}$ in $\mathrm{mL}$, consumed by blank solution and sample solution, respectively.

2.4.4. Peroxide Value. About $5 \mathrm{~g}$ of the test sample was transferred into a $250 \mathrm{~mL}$ conical flask with a glass stopper, and the mixture of 3 volume of glacial acetic acid and 2 volume of chloroform was added gradually with continuous shaking and $0.5 \mathrm{~mL}$ of saturated potassium iodide solution was added. The homogenous sample solution was then allowed to stand for exactly $1 \mathrm{~min}$ with frequent shaking. After that, $20 \mathrm{~mL}$ of the distilled water was poured and subjected to titration against standardized $0.01 \mathrm{~m}$ sodium thiosulphate until the yellow color disappears.

Furthermore, $0.5 \mathrm{~mL}$ of starch solution $(5 \% \mathrm{w} / \mathrm{v}$ in water) was added drop-wise and titration was continued again with vigorous shaking until the blue color just disappears (a $\mathrm{mL}$ ). Blank determination was also performed without a sample (b $\mathrm{mL}$ ). Finally, the peroxide value was calculated by the following equation:

$$
\text { peroxide value }=\frac{10(a-b)}{w},
$$

where $w$ is the weight of the sample in $g$.

2.4.5. Ester Value. Ester value was calculated by using the following equation:

$$
\text { ester value }=\text { saponification value }- \text { acid value } .
$$

2.4.6. Liquefaction Point. The sample was loaded inside a fine capillary tube and the liquefaction point was determined by using digital melting point apparatus.

2.5. Formulation of the $2 \% w / w$ Ketoconazole Ointment. Three different formulations (F-A, F-B, and F-C) of the ketoconazole ointment were prepared by the fusion method [17]. As shown in Table 1, the composition of the formulation was taken from the literature [17], with slight modification. In this technique, all the components were melted together in the decreasing order of their melting points. At first, seed butter was heated to $70^{\circ}$, and then PEG 600, propylene glycol, and Tween 80 were added gradually in it. After that it was cooled up to $40^{\circ} \mathrm{C}$ and ketoconazole was dissolved with continuous sonication assisted agitation for $30 \mathrm{~min}$. Finally, the formulation was filled in aluminum tubes each containing $10 \mathrm{~g}$ of ointment, capped well. All the ointment tubes were stored properly in the air tight bag and bag was stored in a vacuum desiccator at dark and cool place until use. 
TABLE 1: Composition of $2 \% \mathrm{w} / \mathrm{w}$ ketoconazole ointment.

\begin{tabular}{lccc}
\hline Ingredients & \multicolumn{3}{c}{ Formulation } \\
& $\mathrm{A}(\%)$ & $\mathrm{B}(\%)$ & $\mathrm{C}(\%)$ \\
\hline Ketoconazole & 2 & 2 & 2 \\
Seed base & 98 & 81.33 & 48 \\
Tween 80 & - & - & 16.66 \\
Propylene glycol & - & 16.66 & 16.66 \\
PEG6000 & - & - & 16.66 \\
\hline
\end{tabular}

\subsection{Evaluation of the Ointment Formulations}

2.6.1. Visual Examination. The color, odour, and other physical characteristics of the product were noted by visual examination [18].

2.6.2. Spreadability. Excess of sample in between two glass slides $(10 * 10 \mathrm{~cm})$ was placed and a certain load $(2 \mathrm{~kg}$ weight) was placed at the center of the plate. The time required in second to separate the two slides was measured to determine the spreadability. If two slides separate in less time it indicates the good spreadability of the ointment. Spreadability was calculated by the following equation:

$$
S=\frac{M \times L}{T},
$$

where $S$ is spreadability, $M$ is the weight placed to the upper slide, $L$ is the length of glass slide, and $T$ is time taken to separate the slides $[18,19]$.

2.6.3. Extrudability. It gives the information about the force required to extrude the drug material from the tube. The higher the amount of drug extruded, the better the extrudability and quality of the formulation. In this study, the drug sample was filled in a clean collapsible aluminum tube having a nozzle tip with a $5 \mathrm{~mm}$ opening. The pressure was applied to the tube by using a finger. Finally, the percentage of the ointment extruded through the tip was determined by using the following equation [19]:

$$
\% \text { extrudability }=\frac{\text { amount of ointment extruded from the tube }}{\text { total amount of ointment filled in the tube }} \times 100
$$

2.6.4. Average Filling Weight. The net weight of the formulation in the filled containers was determined to ensure that the product contains the uniform and proper amount of sample as labeled. For this analysis, a total of 10 filled tubes were taken and weighed. After that, all the contents of each tube were removed completely and the weight of the empty tube was taken. Finally, the net weight of the drug sample in each tube was calculated and the average fill weight was determined [18].

2.6.5. Washability. Drug sample was spread over the skin and then easiness of washing with water was observed. For this, $1 \mathrm{~g}$ of ointment was rubbed over the hand skin of three healthy humans. After 30 minutes, applied area was washed with normal tap water [17].

2.6.6. Nonirritancy Test. Ointment formulation was applied over the human skin to observe the undesired irritant effect [18].

2.6.7. Determination of $\mathrm{pH}$. The $\mathrm{pH}$ of the ointment solution was measured by using digital a $\mathrm{pH}$ meter. About $1 \mathrm{~g}$ of ointment was suspended in $100 \mathrm{~mL}$ of distilled water and kept for $2 \mathrm{~h}$. The $\mathrm{pH}$ of the each formulation was measured three times.
2.6.8. Viscosity of the Ointment. The viscosity of each formulation was measured by viscometer DV-III ULTRA Brookfield viscometer. About $20 \mathrm{~g}$ of the test sample was placed in a dry and clean $250 \mathrm{~mL}$ beaker. Measurement was done by using spindle no. 64. The data was expressed in centipoises unit (cps). The sample was rotated at $10 \mathrm{rpm}$ for 1 minute. The temperature was maintained up to $25^{\circ} \mathrm{C}$ [20].

\subsubsection{Determination of the Active Ingredient in the Formulation}

(1) Optimization of the HPLC Condition. Quantitative determination of the active ingredient in each formulation was carried out by using the reverse phase HPLC system of prominence-i LC-2030 (Shimadzu, Japan). The chromatographic condition for the analysis was adopted from the method of analysis for ketoconazole raw material (USP 2018) [21].

(2) Method Validation. The validity of the method used for quantitative analysis of ketoconazole ointment formulation was confirmed by analyzing different parameters, namely linearity, limit of detection and quantification (LODs and LOQs), precision (intraday and interday variation and repeatability), and accuracy (recovery) according to ICH guideline [22] and previous study [23-25]. 
(3) Assay of the Ketoconazole Ointments. For the assay, contents of ten random tubes were removed and mixed together, which was then used for HPLC analysis. The assay of each formulation was calculated by [21]

$$
\frac{\text { peak area of } \mathrm{sp}}{\text { peak area of std }} \times \frac{\text { Wstd }}{100} \times \frac{5}{25} \times \frac{100}{\mathrm{Wsp}} \times \frac{25}{5} \times \frac{\text { Purity of std }}{100} \times \frac{(100-\text { LOD })}{100} \times 100 .
$$

where sp is sample, std is standard, Wsp is the weight of the sample ointment taken $(2.5 \mathrm{~g})$, Wstd is the weight of standard drug taken $(50 \mathrm{mg}$ ), and LOD is loss on drying for standard.

(4) Content Uniformity. Randomly 10 ointment tubes were taken from each formulation and assay of each tube was carried out by injecting the samples in HPLC to ensure uniform mixing of ketoconazole in each tube so that every ointment tube contains the labeled amount of active drug.

2.6.10. In Vitro Active Ingredient Release. To investigate the in vitro active ingredient release pattern of the newly formulated ketoconazole ointments, a dialysis method was adopted $[9,20]$. In this method, 3 grams of each formulation was put down on cellophane (semipermeable membrane). The donor compartment which was loaded with an ointment sample was securely pulled up over the lower open end of a glass tube having an internal diameter of $2.5 \mathrm{~cm}$. A rubber band was used to make watertight. The ointment-loaded tube was submerged in a beaker filled with $100 \mathrm{~mL}$ of acetic buffer of pH 5.5 (with $1 \%$ sodium dodecyl sulphate to promote the sink conditions), which acts as active ingredient release medium or receptor compartment. The whole system was set with a magnetic stirrer, and the active ingredient release medium was regularly stirred by using magnetic beads at $50 \mathrm{rpm}$ maintaining the temperature of $37 \pm 0.5^{\circ} \mathrm{C}$ in a thermostatic water bath. After the different time intervals $(0.5,1,2,3,4$, and 5 hours), $1 \mathrm{~mL}$ of solution was withdrawn and immediately replaced with the same volume of fresh buffer by using a micropipette. The amount of the active constituent released from different formulations was determined by the HPLC method.

2.6.11. Accelerated Stability Studies. Stability of the newly formulated ointments was conducted under ICH guideline for accelerated conditions. For this, all the 3 formulations were stored in a stability chamber for 3 months. The condition of stability chamber was $40^{\circ} \mathrm{C} \pm 2^{\circ} \mathrm{C} / 75 \% \mathrm{RH} \pm 5 \% \mathrm{RH}$ [26]. The samples were evaluated for ketoconazole assay, $\mathrm{pH}$ change, smoothness, and color change at the end of first and third month.

2.7. Statistical Analysis. All the experiments were analyzed three times and the data were presented as mean \pm SD. Statistical significance of differences was calculated by twoway analysis of variance (two-way ANOVA) and one-way analysis of variance (one-way ANOVA), with Tukey post hoc test using GraphPad Prism 6.0 software. A $p$ value $<0.05$ was considered to be significant.

\section{Results}

3.1. Physicochemical Analysis of the D. butyracea Seeds Extracts (Chyuri Fat). Different physicochemical properties of the chyuri fat were determined to characterize its present condition and quality (Table 2). Results from our data are compared with most physicochemical parameters of most commonly used vegetable oil (olive oil) [27]. The higher acid value indicates the greater amount of the free fatty acid present in the sample and the lower iodine value signifies that the proportion of saturated fatty acid is high. Similarly, higher saponification value, lower peroxide value, and higher ester value in this sample denote the presence of average molecular weight, less degradable, and higher numbers of saponifiable triglycerides.

\subsection{Evaluation of the $2 \% w / w$ Ketoconazole Ointment} Formulations. After the preparation of 3 different formulations, their qualities were investigated in terms of different parameters (Table 3 ) and were found to be complied. All the formulations were white and viscous with smooth homogenous consistency. From the data of Table 3, it is obvious that all the formulations exhibited good spreadability and extrudability. Similarly, the $\mathrm{pH}$ of all the formulations is within the normal $\mathrm{pH}$ range of the human skin (5.5-7). Analysis of variance (ANOVA) indicated that the formulation $\mathrm{C}$ has significantly less spreadability and extrudability in comparison to formulation B $(p<0.05)$. Formulation C was found to be significantly most viscous among the formulations $(p<0.05)$.

\subsection{Determination of the Active Ingredient in $2 \% \mathrm{w} / \mathrm{w}$ Ketoconazole Ointment Formulations}

3.3.1. Optimization of Chromatographic Conditions. The chromatographic condition described by the USP 2018 for the analysis of active ingredient ketoconazole was tested for the newly formulated ketoconazole ointment. The method was verified for the analysis after ensuring the system suitability and its validity. All the peaks were detected at $225 \mathrm{~nm}$. Figures 3 and 4 represent the chromatograms of blank and placebo, respectively. Similarly, the chromatogram of standard and test sample is depicted in Figure 5.

3.3.2. Method Validation. The chromatographic system was examined for linearity, precision, specificity, and accuracy to confirm the selectivity, reproducibility, and preciseness of the finalized method. The regression coefficient $\left(R^{2}\right)$ of the standard was 1 ; hence the linearity was confirmed. Complete 
TABLE 2: Results of physicochemical characteristics of the D. butyracea seeds hexanolic extract (chyuri fat) compared with olive oil.

\begin{tabular}{lcccccc}
\hline Samples & $\begin{array}{c}\text { Acid value }(\mathrm{mg} \\
\mathrm{KOH} / \mathrm{g})\end{array}$ & $\begin{array}{c}\text { Iodine value }\left(\mathrm{g} \mathrm{I}_{2} /\right. \\
100 \mathrm{~g})\end{array}$ & $\begin{array}{c}\text { Peroxide value } \\
(\mathrm{Meq} \mathrm{KOH} / \mathrm{g})\end{array}$ & $\begin{array}{c}\text { Saponification value } \\
(\mathrm{mg} \mathrm{KOH} / \mathrm{g})\end{array}$ & $\begin{array}{c}\text { Ester value }(\mathrm{mg} \\
\mathrm{KOH} / \mathrm{g})\end{array}$ & $\begin{array}{c}\text { Liquefaction } \\
\text { point }\left({ }^{\circ} \mathrm{C}\right)\end{array}$ \\
\hline $\begin{array}{l}\text { Chyuri } \\
\text { fat }\end{array}$ & $61.86 \pm 1.16$ & $36.26 \pm 0.89$ & $3.14 \pm 0.17$ & $225.05 \pm 1.98$ & $163.19 \pm 2.75$ \\
Olive oil & 4.53 & 76 & 17 & 186.33 & 181.77 & $68 \pm 0.5$ \\
\hline
\end{tabular}

TABLE 3: Evaluation of the different quality control parameters of formulations F-A, F-B, and F-C.

\begin{tabular}{lcccccc}
\hline Formulations & Spreadability $(\mathrm{g} / \mathrm{sec})$ & Extrudability (\%) & $\begin{array}{c}\text { Viscosity } \\
\text { (centipoise) }\end{array}$ & Average fill weight (g) & $\begin{array}{c}\text { pH } \\
\text { Washability and } \\
\text { nonirritancy }\end{array}$ \\
\hline F-A & $5.98 \pm 0.31^{\mathrm{ab}}$ & $66.1 \pm 1.89^{\mathrm{ab}}$ & $305 \pm 1.23^{\mathrm{b}}$ & $10.13 \pm 0.21^{\mathrm{a}}$ & 6.1 & Washable, no irritation \\
F-B & $6.34 \pm 0.25^{\mathrm{a}}$ & $68.2 \pm 1.32^{\mathrm{a}}$ & $297 \pm 0.45^{\mathrm{c}}$ & $10.31 \pm 0.34^{\mathrm{a}}$ & 6.2 & Washable, no irritation \\
F-C & $5.64 \pm 0.19^{\mathrm{b}}$ & $65.2 \pm 0.98^{\mathrm{b}}$ & $310 \pm 0.61^{\mathrm{a}}$ & $10.15 \pm 0.48^{\mathrm{a}}$ & 6.3 & Washable, no irritation \\
\hline
\end{tabular}

Note. Different superscript letters within the same column indicate significant differences $(p<0.05)$ among the formulations.

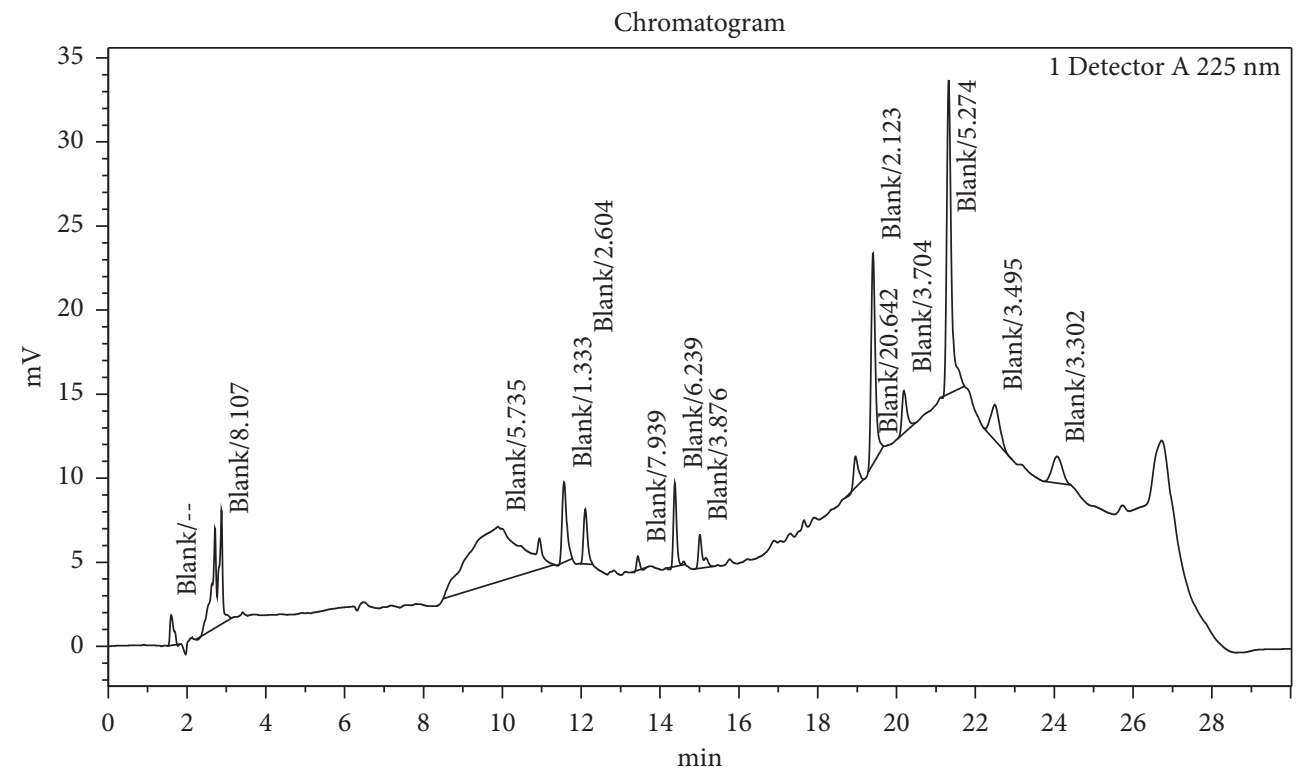

FIGURE 3: HPLC chromatogram of the blank sample (methanol).

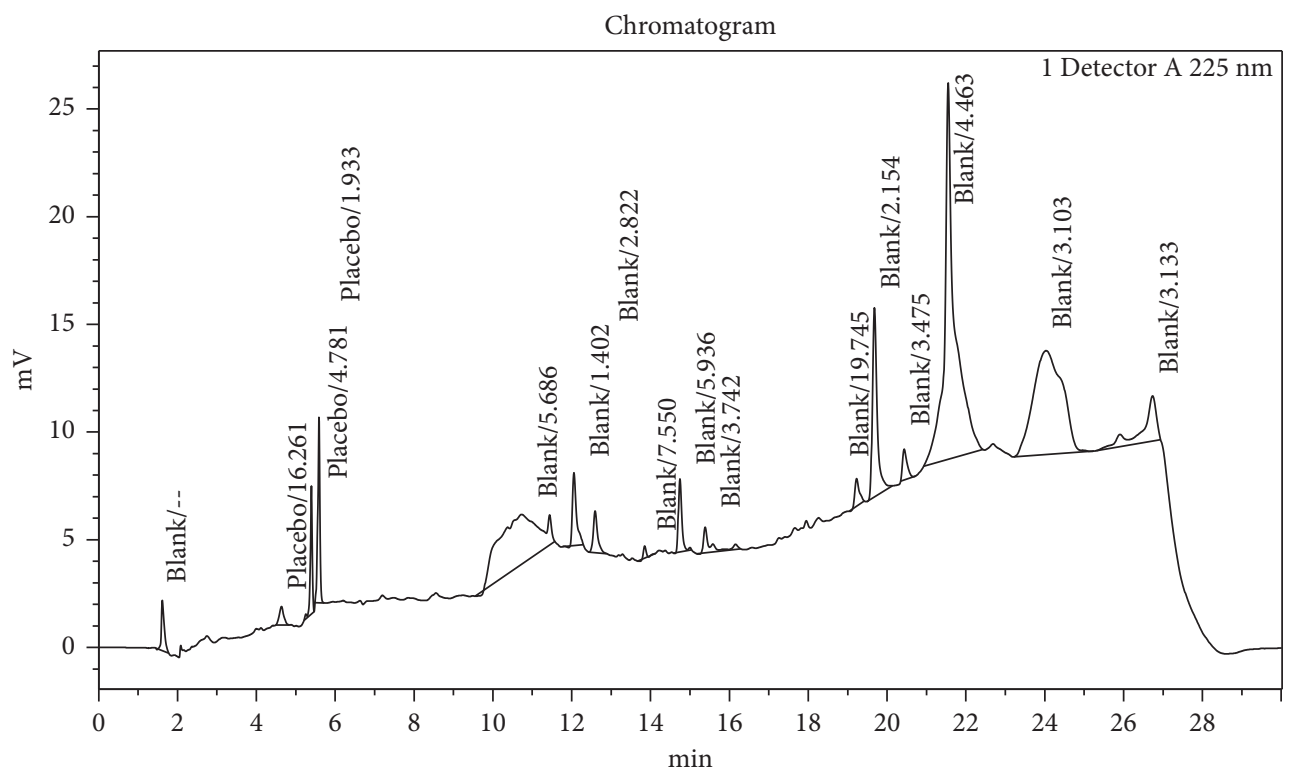

FIgURE 4: HPLC chromatogram of the placebo sample. 


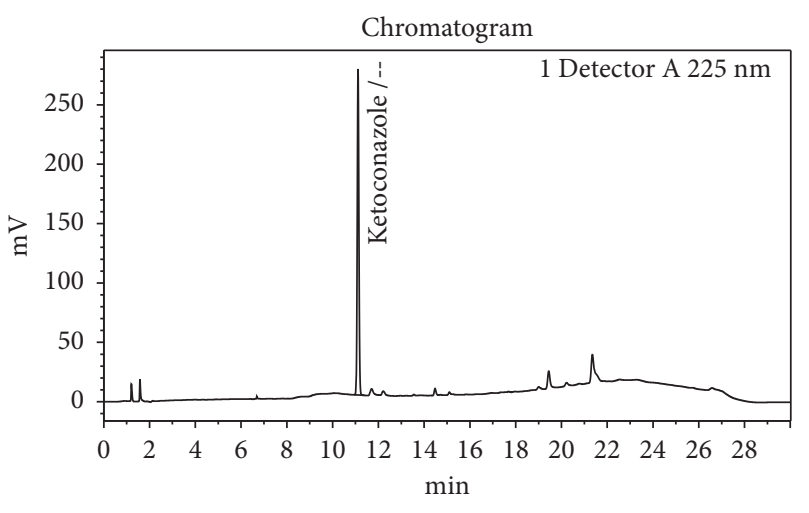

(a)

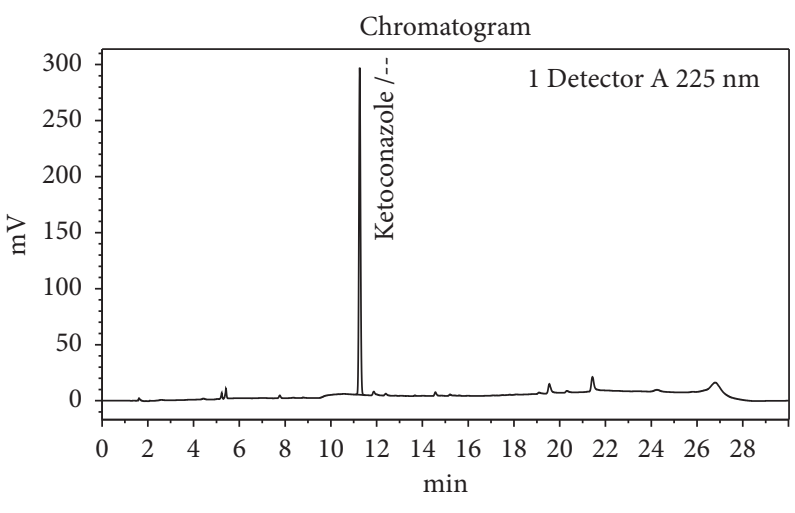

(b)

FIGURE 5: Chromatogram of (a) standard drug ketoconazole and (b) test sample.

information of the calibration curve, LODs, and LOQs is summarized in Table 4.

To confirm the precision of the finalized method, intraday and interday variations together with the repeatability of sextuplates were examined. The relative standard deviations (RSD) for the interday and intraday investigations were found to be in the range of $0.58-0.98 \%$ and $0.11-1.68 \%$, respectively (Table 5).

For the repeatability test of ketoconazole, standard solution was injected six times in a same day. The RSD was reported to be $1.41 \%$ (Table 6).

The recovery percentage was ranged from 95.33 to $104.73 \%$ with RSD value of $0.34-3.48 \%$ (Table 7 ).

In the system suitability examination, average NTP, average tailing actor, and RSD of the area were found to be $91656,1.072$, and 0.33 , respectively, which are in compliance with given criteria of USP 2018.

3.3.3. Assay of the Ketoconazole Ointments. In both initial and accelerated stability study, the active ingredient content of all three formulations was found to be within the limit (95-110\%) specified by US Pharmacopoeia 2018. Slight variation in the active ingredient was found among three different formulations. As shown in Table 8, for all the batches decrease in active ingredient content after one month was statistically significant $((p<0.05)$, whereas after 3 months, a significant decrease in active ingredient content was not observed $(p>0.05)$. Moreover, the content of the active ingredient after accelerated stability in all formulations was within the pharmacopoeial limit.

3.3.4. Content Uniformity of the Different Formulations. To ensure the homogenous mixing of the active ingredient, ketoconazole content of the individual 10 tubes was calculated for each formulation. As shown in Table 9, ketoconazole content in each tube was reported to be within the pharmacopoeial limit.

3.3.5. In Vitro Active Ingredient Release. Results of the in vitro active ingredient release evaluation by using the dialysis method are depicted in Table 10. For statistical analysis
TABLE 4: Regression data, LODs, and LOQs for ketoconazole determined by HPLC.

\begin{tabular}{lcccc}
\hline Standard & Regression equation & $R^{2}$ & $\begin{array}{c}\text { LODs } \\
(\mu \mathrm{g} / \mathrm{mL})\end{array}$ & $\begin{array}{c}\text { LOQs } \\
(\mu \mathrm{g} / \mathrm{mL})\end{array}$ \\
\hline Ketoconazole & $y=14143 x-5907.4$ & 1 & 0.513 & 1.449 \\
\hline
\end{tabular}

$x$ : concentration in $\mu \mathrm{g} / \mathrm{mL} ; y=$ peak area.

of active ingredient release percentage (\%), we used two-way ANOVA to compare the active ingredient release pattern among the formulations in different time intervals, so two variable factors were 3 different formulations and different time intervals from $0.5 \mathrm{~h}$ to $5 \mathrm{~h}$. The extent of the active ingredient released was proportional to the time increased. The release pattern of formulation A was almost similar to the F-B and F-C. This signifies that the formulation of the ointment by using chyuri fat only can ensure the desired active ingredient release of the formulation.

\section{Discussion}

The acid value of the fat gives the information about the amount of short-chain free fatty acid present in it. In most cases, it is the evaluation of the extent of triglycerides decomposition by lipase enzyme activity, light, and heat $[28,29]$. It gives an idea about the edibility of the fat. The fat or oil substance with an acid value higher than $4 \mathrm{mg} / \mathrm{g}$ is considered to be unsuitable for the edible process [30]. The higher acid value of chyuri fat $(61.86 \mathrm{mg} \mathrm{KOH} / \mathrm{g})$ suggests that its consumption is not beneficial for human health. The iodine value gives information about the average degree of unsaturation. It is used to quantify the numbers of double bonds in the fat which are susceptible to oxidative degradation [31]. The lower iodine value of the chyuri fat (36.26g $\mathrm{I}_{2} / 100 \mathrm{~g}$ ) indicated that it contains a higher proportion of saturated fatty acids. Major fatty acids present in chyuri fat are methyl ester formed of saturated palmitic acid (66\%), saturated stearic acid $(2.4 \%)$, monounsaturated linoleic acid (26\%), and polyunsaturated oleic acid (2.6\%), indicating stability of the fat towards lipid peroxidation $[8,32]$. Fat or oil samples having the iodine value lower than $100 \mathrm{~g} \mathrm{I}_{2} / 100 \mathrm{~g}$ are suitable for industrial uses [33] like bakery production, 
TABLE 5: Analytical results of intraday and interday variation.

\begin{tabular}{|c|c|c|c|c|c|}
\hline \multirow{2}{*}{ Standard } & \multirow{2}{*}{ Concentration $(\mu \mathrm{g} / \mathrm{mL})$} & \multicolumn{2}{|c|}{ Intraday } & \multicolumn{2}{|c|}{ Interday } \\
\hline & & Mean \pm SD & RSD (\%) & Mean \pm SD & RSD (\%) \\
\hline \multirow{3}{*}{ Ketoconazole } & 125 & $127.97 \pm 0.14$ & 0.11 & $127.36 \pm 1.23$ & 0.96 \\
\hline & 62.5 & $62.79 \pm 0.31$ & 0.49 & $63.68 \pm 0.37$ & 0.58 \\
\hline & 31.25 & $31.54 \pm 0.53$ & 1.68 & $31.76 \pm 0.31$ & 0.98 \\
\hline
\end{tabular}

TABLE 6: Repeatability of standard ketoconazole.

\begin{tabular}{lcccc}
\hline Standard & Amount \pm SD $(\mu \mathrm{g} / \mathrm{ml})$ & RSD $(\%)$ & $T_{r}(\min ) \pm$ SD & RSD $(\%)$ \\
\hline Ketoconazole & $129.55 \pm 1.83$ & 1.412582015 & $11.72 \pm 0.1$ & 0.853242321 \\
\hline
\end{tabular}

TABLE 7: Recovery of data of standard compound spiked in ointment samples.

\begin{tabular}{|c|c|c|c|c|c|}
\hline Standards & Spiked $(\mu \mathrm{g} / \mathrm{mL})$ & Measured $(\mu \mathrm{g} / \mathrm{mL})$ & RSD (\%) & Recovery (\%) & Mean recovery (\%) \\
\hline \multirow{3}{*}{ F-A } & 125 & $129.55 \pm 2.78$ & 2.14 & 103.64 & \multirow{3}{*}{101.31} \\
\hline & 62.5 & $61.35 \pm 1.12$ & 1.83 & 98.16996 & \\
\hline & 31.25 & $33.79 \pm 0.13$ & 0.403 & 102.130 & \\
\hline \multirow{3}{*}{ F-B } & 125 & $150.6041 \pm 1.76$ & 2.14 & 103.64 & \multirow{3}{*}{102.13} \\
\hline & 62.5 & $61.94547 \pm 0.21$ & 0.34 & 99.11275 & \\
\hline & 31.25 & $32.3958 \pm 1.12$ & 3.48 & 103.6665 & \\
\hline \multirow{3}{*}{ F-C } & 125 & $119.1653 \pm 1.09$ & 0.91 & 95.33227 & \multirow{3}{*}{98.79} \\
\hline & 62.5 & $55.82011 \pm 1.2$ & 2.23 & 96.31217 & \\
\hline & 31.25 & $33.97908 \pm 1.42$ & 2.18 & 104.733 & \\
\hline
\end{tabular}

TABLE 8: Total active ingredient content of the formulations A, B, and C in the initial and accelerated stability testing. Assay of all the formulations was done by pharmacopoeial method.

\begin{tabular}{lccc}
\hline Formulations & Initial assay & Stability assay (after 1 month) & Stability assay (after 3 months) \\
\hline F-A & $103.01 \pm 1.21 \%^{\mathrm{a}}$ & $99.1 \pm 0.76 \%^{\mathrm{b}}$ & $98.55 \pm 0.67 \%^{\mathrm{b}}$ \\
F-B & $107.9 \pm 0.32 \%^{\mathrm{a}}$ & $98.5 \pm 0.85 \%^{\mathrm{b}}$ & $97.05 \pm 0.21 \%^{\mathrm{b}}$ \\
F-C & $102.45 \pm 1.65 \%^{\mathrm{a}}$ & $99.1 \pm 1.01 \%^{\mathrm{ab}}$ & $97.7 \pm 0.56 \%^{\mathrm{b}}$ \\
\hline
\end{tabular}

Note. Different superscript letters within the same row indicate significant differences $(p<0.05)$ among the formulation.

TABLE 9: Total ketoconazole content of the different 10 tubes of formulations $\mathrm{A}, \mathrm{B}$, and $\mathrm{C}$ in the content uniformity analysis as per the pharmacopoeial method.

\begin{tabular}{|c|c|c|c|}
\hline Test & Assay of formulation A (\%) & Assay of formulation B (\%) & Assay of formulation C (\%) \\
\hline 1 & 102.02 & 104.29 & 102.77 \\
\hline 2 & 102.44 & 104.38 & 104.75 \\
\hline 3 & 103.05 & 103.31 & 103.92 \\
\hline 4 & 103.05 & 103.67 & 104.57 \\
\hline 5 & 103.62 & 103.23 & 104.04 \\
\hline 6 & 102.57 & 104.08 & 104.43 \\
\hline 7 & 103.50 & 104.80 & 102.85 \\
\hline 8 & 103.42 & 102.99 & 103.46 \\
\hline 9 & 103.89 & 102.25 & 104.68 \\
\hline 10 & 101.72 & 103.82 & 104.92 \\
\hline
\end{tabular}

TABle 10: Percentage of drug release for the formulations F-A, F-B, and F-C in acetic acid buffer at different time intervals.

\begin{tabular}{lcccccc}
\hline \multirow{2}{*}{ Formulations } & \multicolumn{5}{c}{ Active ingredient release percentage (\%) } \\
& 0.5 hours & 1 hour & 2 hours & 3 hours & 4 hours & 5 hours \\
\hline F-A & $15.93 \pm 0.77^{\mathrm{a}}$ & $27.32 \pm 0.66^{\mathrm{a}}$ & $42.03 \pm 2.01^{\mathrm{a}}$ & $66.35 \pm 0.98^{\mathrm{a}}$ & $75.15 \pm 0.87^{\mathrm{a}}$ & $87.71 \pm 1.44^{\mathrm{a}}$ \\
F-B & $17.17 \pm 0.86^{\mathrm{a}}$ & $30.40 \pm 0.61^{\mathrm{b}}$ & $45.3 \pm 1.08^{\mathrm{b}}$ & $67.3 \pm 1.18^{\mathrm{a}}$ & $77.8 \pm 0.41^{\mathrm{ab}}$ & $88.89 \pm 0.67^{\mathrm{a}}$ \\
F-C & $18.3 \pm 0.23^{\mathrm{a}}$ & $31.12 \pm 091^{\mathrm{c}}$ & $44.07 \pm 0.68^{\mathrm{ab}}$ & $70.19 \pm 0.45^{\mathrm{b}}$ & $79.18 \pm 0.8^{\mathrm{b}}$ & $91.09 \pm 0.19^{\mathrm{b}}$ \\
\hline
\end{tabular}

Note. Different superscript letters within the same column indicate significant differences $(p<0.05)$ among the formulations. 
margarine production, cosmetic industry, and drug industry [34]. The low iodine value of any fat or oil ensures its stability against oxidation and rancidity of products prepared with it $[33,34]$.

The stability of the fat against possible rancidity was also verified by the lower peroxide value ( $3.14 \mathrm{Meq} \mathrm{KOH} / \mathrm{g}$ ), obtained in this study. Peroxide value is an indication of possible autooxidation; hence low value ensures that it can resist peroxidation in the course of storage [31]. Similarly, the saponification value $(225.05 \mathrm{mg} \mathrm{KOH} / \mathrm{g})$ and ester value (163.19 mg KOH/g) of the chyuri fat were reported to be high. The higher saponification and ester value indicates that fat contains a large proportion of short-chain lower molecular weight and saponifiable triglycerides, respectively. This type of fat is suitable for cosmetic and industrial purposes $[28,33]$. Moreover, the liquefaction point $\left(68^{\circ} \mathrm{C}\right)$ of this fat also ensures its suitability for the ointment base [35].

After the confirmation of its chemical stability to use as an ointment base, $2 \% \mathrm{w} / \mathrm{w}$ ketoconazole ointment was formulated by fusion method and quality was evaluated. Physically, all the ointment formulations were smooth viscous preparation without any grittiness and white. No skin irritations were observed after applications and all the formulations were easily washable. Also, the $\mathrm{pHs}$ of all the formulations were within the normal $\mathrm{pH}$ condition of the human skin (5.5-7) [17]. From the one-way analysis of variance (ANOVA), it was evident that viscosity of the formulation $\mathrm{C}$ was significantly high among all $(p<0.05)$. Also, the viscosity of formulation $A$ was higher than B. Incorporation of the PEG 6000 and Tween 80 in the formulation $\mathrm{C}$ might be the contributing factor for its highest viscosity $[17,20]$. The higher viscosity of formulation $\mathrm{A}$ as compared to formulation $\mathrm{B}$ might be due to the higher proportion of chyuri fat in formulation A. Formulation B was found to be more extrudible and spreadable than other formulations and the difference in these parameters of formulations B and C were statistically significant $(p<0.05)$.

In vitro active ingredient release study is an important analytical step to evaluate the extent of active release from the medicinal product matrix in controlled laboratory condition during the process of drug development and quality control analysis [36]. The active ingredient release investigation of all the 3 formulations, conducted by using dialysis method (Table 10), revealed the satisfactory result. The two-way ANOVA test was applied to evaluate the statistical significance of release pattern. It was found that there was increase in the active ingredient release in every hour and was significant at $p<0.05$. After $5 \mathrm{~h}$, the active ingredient release profile of formulation $\mathrm{C}$ was more significant than $\mathrm{A}$ and $\mathrm{B}$. This might be due to the addition of Tween 80 and PEG 6000. Formulation A was composed of ketoconazole (2\%) and natural chyuri fat (98\%). In formulation B, propylene glycol $(16.66 \%)$ as a solubilizer [17] was added in addition to active drug (2\%) and chyuri fat $(81.33 \%)$. In the case of formulation C, Tween $80(16.66 \%)$ as a surfactant [19] and PEG $6000(16.66 \%)$ as a water solubilizing base [37] were also incorporated along with ketoconazole (2\%), chyuri base (48\%), and propylene glycol $(16.66 \%)$. Ketoconazole release percentages of formulations
$\mathrm{A}, \mathrm{B}$, and $\mathrm{C}$ were almost similar throughout the study. While comparing formulations $\mathrm{A}$ and $\mathrm{B}$, the percentage of the active constituent was very slightly higher in formulation $B$, which may be due to the incorporation of propylene glycol. However, there was no statistically significant variation between these formulations $(p>0.05)$ except at 1 and 2 hours $(p<0.05)$. Despite the higher viscosity of formulation $C$, active ingredient release profile was slightly better than A and $\mathrm{B}$. This might be due to the addition of Tween 80 and PEG 6000. This is because Tween 80 improves the uniform solubilization of drug all over the vehicle [19] and PEG 6000 enhances penetration of water to promote rapid release of active principle [37]. Due to its high polarity, PEG play significant role in increasing the hydrophilicity and thus enhances water solubility. Therefore, it is widely used in ointment for solubilization and permeation [37]. The active ingredient release pattern of F-A which was almost similar to the F-B and F-C, which signifies that the formulation of the ointment by using chyuri fat only can ensure the desired release of active constituent.

To confirm the homogenous mixing of the active ingredient in all formulations, 10 randomly selected tubes from each formulation were taken and ketoconazole content was determined. Content of ketoconazole in formulations A, $\mathrm{B}$, and C ranged from $101.72-103.89 \%, 102.55-104.80 \%$, and $102.77-104.92 \%$, respectively. All the formulations were within the pharmacopoeial range. The formulated ointments were investigated for accelerated stability study according to ICH guidelines for up to three months. The results of accelerated stability studies revealed that no formulation suffered from evident physical and chemical change (color, phase separation, smoothness, and $\mathrm{pH}$ ). Content of the active constituent that decreased for formulation B over the 3-month stability showed significant change (107.9-97.05\%) in comparison to formulation A (103.01-98.55\%) and formulation C (102.45-97.7\%). However, assay of all the formulation was within the pharmacopoeial limit (90-110\%) [21] after 3 months of accelerated study. Further advance stability investigations, which were beyond the range of this study, are required to determine the shelf-life of these formulations.

\section{Conclusions}

In summary, the present research work evaluated the physicochemical parameters (acid value, iodine value, saponification value, peroxide value, ester value, $\mathrm{pH}$, and liquefaction point) of chyuri fat and it concluded that the fat is highly recommended for the industrial, cosmetic, and pharmaceutical purpose. The high acid value suggested its unsuitability for the edible use. Furthermore, the ointment formulation F-A which was prepared by using chyrui fat only, for the first time, gave satisfactory results related to its physical and chemical stability. Various evaluation parameters such as spreadability, extrudability, viscosity, average fill weight, active principle content, content uniformity, accelerated stability, and active ingredient release profile were within the acceptable range and almost similar to the $\mathrm{F}-\mathrm{B}$ and F-C in which synthetic base was incorporated. Thus, 
further extensive study is recommended so that chyuri fat can be established as a better alternative for other synthetic base and its commercialization may improve the socioeconomic status of the local people.

\section{Data Availability}

All the data used to support the result of this research are available from R. Bhandari and J. Pandey upon request.

\section{Disclosure}

This research project was performed as part of the partial fulfillment of academic degree at Crimson College of Technology, Nepal.

\section{Conflicts of Interest}

The authors declare no conflicts of interest.

\section{Authors' Contributions}

R. Bhandari and J. Pandey conceived and designed the experiment and analyzed the data. J. Pandey, B. Khanal, J. Bhandari, A. Pandey, and R. Bashyal performed the experiment. J. Pandey wrote the manuscript. P. Aryal, J. Pandey, Ravin Bhandari, and AA. Mikrani contributed to the paper revision. J. Pandey and R. Bhandari equally contributed to this work.

\section{Acknowledgments}

The authors are very much grateful to Crimson College of Technology, affiliated to Pokhara University, Nepal, for all the technical support. The authors would also like to remember Dr. Amrit Poudel, Dr. Hari Prasad Devkota, Dr. Dhaka Ram Bhandari, and Biogain of Remedies Private Limited, Nepal, for the guidance and technical support.

\section{References}

[1] H. P. Devkota, T. Watanabe, K. J. Malla, Y. Nishiba, and S. Yahara, "Studies on medicinal plant resources of the himalayas: GC-MS analysis of seed fat of chyuri (Diploknema butyracea) from Nepal," Pharmacognosy Journal, vol. 4, no. 27, pp. 42-44, 2012.

[2] S. Tiwari, S. Nepal, S. Sigdel et al., "Phytochemical screening, antibacterial-guided fractionation, and thin-layer chromatographic pattern of the extract obtained from Diploknema butyracea," Pharmacognosy Research, vol. 12, no. 4, pp. 437443, 2020.

[3] R. Rashmi and S. Tyagi, "Phytochemical standardization of Diploknema butyracea (Roxb.) H. J. Lam. seeds by HPTLC technique," Indian Journal of Natural Products and Resources, vol. 6, no. 4, pp. 299-304, 2015.

[4] N. C. Joshi, A. Chaudhary, and G. S. Rawat, "Cheura (Diploknema butyracea) as a livelihood option for forest-dweller tribe (Van-Raji) of Pithoragarh, Uttarakhand, India," Essence International Journal for Environmental Rehabilitation and Conservation, vol. 9, no. 1, pp. 134-141, 2018.

[5] T. Watanabe, K. R. Rajbhandari, K. J. Malla, H. P. Devkota, and S. Yahara, A Handbook of Medicinal Plants of Nepal
Supplement I, Ayurseed Life Environmental Institute, Kanagawa, Japan, 2013.

[6] N. P. Manandhar, Plants and People of Nepal, Timber Press, Portland, OR, USA, 2002.

[7] M. R. Shakya, "Chepangs and Chiuri-the use of non-timber forest products in Nepal," Food Chain, vol. 26, pp. 3-5, 2000.

[8] M. K. Adhikari, D. M. Shakya, M. Kayastha, and S. R. Baral, Bulletin of Department of Plant Resources No. 28. Medicinal Plants of Nepal (Revised), Department of Plant Resources, Kathmandu, Nepal, 2007.

[9] G. Rajalakshmi, N. Damodharan, V. K. V. B. Chaudhari, and J. R. Pogal, "Formulation and evaluation of clotrimazole and ichthammol ointment," International Journal of Pharma Bio Sciences, vol. 1, no. 4, pp. 7-16, 2010.

[10] S. Shirsand, K. Kanani, D. Keerthy, D. Nagendrakumar, and M. Para, "Formulation and evaluation of Ketoconazole niosomal gel drug delivery system," International Journal of Pharmaceutical Investigation, vol. 2, no. 4, pp. 201-208, 2012.

[11] S. S. Rane and P. Padmaja, "Spectrophotometric method for the determination of ketoconazole based on amplification reactions," Journal of Pharmaceutical Analysis, vol. 2, no. 1, pp. 43-47, 2012.

[12] S. Naveed and L. Jaweed, "UV spectrophotometric assay of Ketoconazole oral formulations," American Journal of Life Sciences, vol. 2, no. 5, pp. 108-111, 2014.

[13] Y. Tsume, N. Igawa, A. J. Drelich, G. E. Amidon, and G. L. Amidon, "The combination of GIS and biphasic to better predict in vivo dissolution of BCS class IIb drugs, ketoconazole and raloxifene," Journal of Pharmaceutical Sciences, vol. 107, no. 1, pp. 307-316, 2018.

[14] F. D. Choi, M. L. W. Juhasz, and N. Atanaskova Mesinkovska, "Topical ketoconazole: a systematic review of current dermatological applications and future developments," Journal of Dermatological Treatment, vol. 30, no. 8, pp. 760-771, 2019.

[15] K. Winnicka, M. Wroblewska, P. Wieczorek, P. T. Sacha, and E. Tryniszewska, "Hydrogel of Ketoconazole and PAMAM dendrimers: formulation and antifungal activity," Molecules, vol. 17, no. 4, pp. 4612-4624, 2012.

[16] Government of India, Indian Pharmacopoeia, Controller of Publications, Delhi, India, 2018.

[17] R. T. Jadhav, P. R. Patil, and P. H. Patil, "Formulation and evaluation of semisolid preparation (Ointment, Gel \& Cream) of thiocolchicoside," Journal of Pharmaceutical and Biomedical Sciences, vol. 8, no. 8, pp. 1-6, 2011.

[18] S. E. Sawant and M. D. Tajane, "Formulation and evaluation of herbal ointment containing neem and turmeric extract," Journal of Scientific and Innovative Research, vol. 5, no. 4, pp. 149-151, 2016.

[19] C. M. Chakole, M. A. Shende, and S. N. Khadatkar, "Formulation and evaluation of novel combined halobetasol propionate and fusidic acid ointment," International Journal of Chemistry Research, vol. 1, no. 1, pp. 103-116, 2009.

[20] A. Mekkawy, M. Fathy, and S. El-Shanawany, "Study of fluconazole release from o/w cream and water soluble ointment bases," British Journal of Pharmaceutical Research, vol. 3, no. 4, pp. 686-696, 2013.

[21] United States Pharmacopoeia Convention, The United States Pharmacopoeia, United States Pharmacopeial Convention, Rockville, Maryland, USA, 41 edition, 2018.

[22] US FDA Federal Register, International Conference of Harmonization Q2B: Validation of Analytical Procedures Methodology, US FDA Federal Register, College Park, MD, USA, 1997. 
[23] A. Poudel, J. Pandey, and H.-K. Lee, "Geographical discrimination in curcuminoids content of turmeric assessed by rapid UPLC-DAD validated analytical method," Molecules, vol. 24, no. 9, p. 1805, 2019.

[24] J. Pandey, T. Bastola, J. Tripathi et al., "Estimation of total quercetin and rutin content in Malus domestica of Nepalese origin by HPLC method and determination of their antioxidative activity," Journal of Food Quality, vol. 2020, Article ID 8853426, 13 pages, 2020.

[25] S. Koirala, P. Nepal, G. Ghimire et al., "Formulation and evaluation of mucoadhesive buccal tablets of aceclofenac," Heliyon, vol. 7, no. 3, p. e06439, 2021.

[26] R. Thakkar, E. A. Ashour, A. Shukla et al., "A comparison between lab-scale and hot-melt-extruder-based anti-inflammatory ointment manufacturing," AAPS PharmSciTech, vol. 21 , no. 5, pp. 200-214, 2020.

[27] A. Muhammad, M. Ayub, A. Zeb, S. Wahab, and S. Khan, "Physicochemical analysis and fatty acid composition of oil extracted from olive fruit," Food Science and Quality Management, vol. 19, no. 1, pp. 1-6, 2013.

[28] U. V. Inekwe, M. O. Odey, B. Gauje, A. M. Dakare, C. D. Ugwumma, and E. S. Adegbe, "Fatty acid composition and physicochemical properties of Jatropha Curcas oils from Edo and Kaduna states of Nigeria and India," Annals of Biological Research, vol. 3, no. 10, pp. 4860-4864, 2012.

[29] A. T. Oladiji, M. T. Yakubu, A. S. Idoko, O. Adeyemi, and M. O. Salawu, "Studies on the physicochemical properties and fatty acid composition of the oil from ripe plantain peel (Musa paradisiaca)," Scientific African, vol. 11, no. 1, pp. 73-78, 2010.

[30] I. A. Amoo, A. F. Eleyinmi, N. O. A. Ilelaboye, and S. S. Akoja, "Characterisation of oil extracted from gourd (Cucurbita maxima) seed," Journal of Food Agriculture and Environment, vol. 2, no. 2, pp. 38-39, 2004.

[31] M. O. Bello, T. L. Akindele, D. O. Adeoye, and A. O. Oladimeji, "Physicochemical properties and fatty acids profile of seed oil of Telfairia occidentalis Hook," International Journal of Sciences: Basic and Applied Research, vol. 11, no. 6, pp. 09-14, 2011.

[32] S. Alireza, C. P. Tan, M. Hamed, and M. Y. B. Che, "Effect of frying process on fatty acid composition and iodine value of selected vegetable oils and their blends," International Food Research Journal, vol. 17, no. 2, pp. 295-302, 2010.

[33] N. U. Chinedu, A. Benjamin, and A. Peter, "Chemical composition and physicochemical analysis of matured stems of Opuntia dillenii grown in Nigeria," Food Science and Technology, vol. 5, no. 5, pp. 106-112, 2017.

[34] C. Bariwere Samuel, K. K. Barine, and E. E. Joy, "Physicochemical properties and fatty acid profile of shea butter and fluted pumpkin seed oil, a suitable blend in bakery fat production," International Journal of Nutrition and Food Sciences, vol. 6, no. 3, pp. 122-128, 2017.

[35] A. M. Bhagurkar, M. Angamuthu, H. Patil et al., "Development of an ointment formulation using hot-melt extrusion technology," AAPS PharmSciTech, vol. 17, no. 1, pp. 158-166, 2016.

[36] A. M. El Gendy, H. W. Jun, and A. A. Kassem, "In vitro release studies of flurbiprofen from different topical formulations," Drug Development and Industrial Pharmacy, vol. 28, no. 7, pp. 823-831, 2002.

[37] A. A. D'souza and R. Shegokar, "Polyethylene glycol (PEG): a versatile polymer for pharmaceutical applications," Expert Opinion on Drug Delivery, vol. 13, no. 9, pp. 1257-1275, 2016. 